\title{
A COMPARISON OF BODY MASS INDEX AND WEIGHT GAIN AMONG MALE SPRAGUE DAWLEY RATS ON BROILER AND DOMESTIC CHICKEN MEAT FEED
}

\author{
Hammad Gul Khan, Amir Rashid, Zainab Khan*, Faiza Aman**, Muhammad Shoaib** \\ Army Medical College/National University of Medical Sciences (NUMS) Rawalpindi Pakistan, *Khyber Medical University, \\ Peshawar Pakistan, **Quaid-e-Azam University, Islamabad Pakistan
}

\begin{abstract}
Objective: To compare and evaluate the effects of broiler chicken fed with commercially offered feed and chicken fed with organic diet on body mass index and weight gain in male Sprague Dawley rats.

Study Design: Laboratory based experimental study.

Place and Duration of Study: Multi-Disciplinary Laboratory of Department of Biochemistry and Molecular Biology, Army Medical College, Rawalpindi, and collaborated with Quaid-e-Azam University, Islamabad, from Nov 2017 to Apr 2019.

Methodology: Ninety male early weaned Sprague Dawley rats were arbitrarily assorted into three groups $(n=30)$. Group I control rats were nourished on standard pelleted diet. Group II rats were nourished with organic chicken meat along with their standard pelleted diet. Group III rats were nourished with broiler chicken meat along with their standard pelleted diet. Body mass index and weight gain were estimated. All variables were calculated as Mean \pm SD values. One-way ANOVA was applied to determine the significance among groups followed by Tuckey's HSD post hoc test. $p$-value $\leq 0.05$ was considered significant.

Results: The current study demonstrated significant increase inbody mass index $(p \leq 0.001)$ and weight gain $(p \leq 0.001)$ in broiler chicken meat treated group as compared to control and organic chicken meat treated groups.

Conclusion: Based on the findings of our study we concluded that broiler chicken meat consumption could be the probable cause of weight imbalances and out of proportion gain of weight and growth in experimental rats.
\end{abstract}

Keywords: Body mass index, Broiler chicken, Growth rate, Organic chicken, Organic diet, Sprague dawley rats.

This is an Open Access article distributed under the terms of the Creative Commons Attribution License (http://creativecommons.org/licenses/by/4.0), which permits unrestricted use, distribution, and reproduction in any medium, provided the original work is properly cited.

\section{INTRODUCTION}

The consumption of chicken as an essential source of animal protein has displayed an immense upsurge globally over the passage of time and is being used as a staple food worldwide because of its easy accessibility, pleasant taste, relatively reasonable price, nutritional value and acceptance by all echelons of society with various backgrounds ${ }^{1}$. The increasing worldwide population, shared with factors such as amplified pressure on the world's resources, changing sociodemographics and augmented demand for animal-based protein, resulted in chicken meat as popular alternative source for protein ${ }^{2}$.

The consumption of globalchicken meat in 2018 averaged $13.9 \mathrm{~kg}$ per capita ${ }^{3}$. Consumption of chicken meat in Asia, increased from $6.6 \mathrm{~kg}$ to

Correspondence: Dr Hammad Gul Khan, Department of Biochemistry, Army Medical College Rawalpindi Pakistan

Received: 30 Jan 2020; revised received: 24 Jun 2020; accepted: 17 Jul 2020
$9.5 \mathrm{~kg}$ per capita per year ${ }^{1}$. In Pakistan poultry consumption is $4.4 \mathrm{~kg} /$ capita 3 in 2017. In 2025, the poultry consumption per capita in Pakistan is anticipated to amount to approximately 4.68 kilograms per individual per annum ${ }^{4}$. Presently revenue generated by Poultry Industry in Pakistan is about 750 Billion rupees. Poultry sector produces employment and profits for about 1.5 million people.

The current sources of poultry in vogue are broiler and domestic. The former is the most reasonable and accessible in local marketplaces and is nourished on commercially offered feed. While the latter one is difficult to acquire due to high cost and shortage. There is an inclination towards poultry meat instead of red meat because of delicious taste, diminutive price and easy accessibility. Modern broiler has 150 to 200 grams of fat per $\mathrm{kg}$ body of its weight ${ }^{5}$, which is 15$20 \%$ more fat $^{6}$, than that of indigenous/organic 
chicken. Of this additional fat $>85 \%$ is not physiologically required 7 . Diet, especially fat enriched plays significant role in hormonal imbalance, obesity and hyperlipidemias. Synthetic estrogens and other compounds having androgenic and progestogenic properties have been in practice for growth promotion and to improve carcass quality in chicken.

Some essential ingredients included in poultry feed are steroids, antibiotics, minerals and arsenic which might be used intentionally for the higher boom and overall performance of the chickens $^{8}$. The elements of the chicken feed are stated to impart higher flavor and increased growth rateand meat quantity in chickens and as a result more and more chicken is consumed on daily basis. As broiler chicken meat contains extra fat and increased nitrogenous compounds so imparting humans with extra fat and proteins. The existence of the certain substances mainly oysters shells and roxersone from infected waters, antibiotics, fat from previous bird debris and hormones extracts making up the feed of the chicken might also deliver dangerous effects to the people ingesting the meat.

With increased consumption of poultry meat, it is a growing myth in general public that broiler chicken consumption may not be safe and is commonly believed to be an estrogenic, carcinogenic as well as growth retardant. It is a growing concern not in general public but also among the clinicians that broiler chicken consumption may lead to obesity ${ }^{9}$, reproductive disorders ${ }^{10}$, such as precocious puberty, hirsutism, polycystic ovarian syndrome, early menarche and menopause. We have conducted a comparative study to determine the effects onbody mass index and weight gainin response to chicken fed with commercially available feed and chicken fed with organic diet.

\section{METHODOLOGY}

A total number of 90 early weaned Sprague Dawley rats weighing 45-60 grams and between ages of $3-4^{11}$, weeks were obtained from inbred colony of animal house of Quaid-e-Azam
University, Islamabad. Laboratory based experimental study was conducted in the Multidisciplinary laboratory, Biochemistry Department, Army Medical College, Rawalpindi, from November 2017 to April 2019. The Ethics Review Committee reviewed the ethical aspects of the venture and was contented with the undertaking of the investigators and they were in line with the approvals of National Institute of Health Guide for Care and Use of Laboratory Animals (Publication No. 85-23, revised 1985) ${ }^{12}$. Non-probability consecutive sampling was employed to split rats into three groups, group I, II and III with 30 rats allocated to each group. The group I control rats were fed on standard pelleted rat diet and water ad libitum while group II were fed on standard diet supplemented with organic chicken meat and group III were fed on standard diet supplemented with broiler chicken meat forten weeks' time. At the end of the study weight, the abdominal circumference $(\mathrm{AC})$ (immediately anterior to the forefoot), thoracic circumference (immediately behind the foreleg), body length (nose-toanus or nose-anus length) were measured in all rats. The measurements were made in sedated rats $(0.1 \mathrm{~mL}$ intraperitoneally of $1 \%$ sodium barbiturate). The body weight and body length were used to calculate the body mass index ${ }^{13}$.

Body mass index = body weight $(\mathrm{g}) /$ length $^{2}$ $\left(\mathrm{cm}^{2}\right)$. Growth rate is also calculated at the end.

The data analysis was performed using SPSS version 22. Quantitative data was presented in terms of mean and SD. Data distribution was checked using Shapiro Wilk test. One-way ANOVA was applied to gauge the statistical significance among the groups (data was found to be uniform or non-skewed). $p$-value of $\leq 0.05$ was considered significant and group differences were calculated using Post Hoc test (Tukey HSD).

\section{RESULTS}

A comparison of the mean body mass index and weight gain among the three groups at the end of ten weeks is shown in table. Mean body mass index of the three groups (I, II, III) was 0.61 $\pm 0.03 \mathrm{~g} / \mathrm{cm}^{2}, 0.72 \pm 0.02 \mathrm{~g} / \mathrm{cm}^{2}$ and $0.81 \pm 0.01$ 
$\mathrm{g} / \mathrm{cm}^{2}$ respectively. Similarly mean weight gain in group I, II and III was $190.27 \pm 17.57 \mathrm{~g}, 185.30 \pm$ $17.41 \mathrm{~g}$ and $229.17 \pm 16.88 \mathrm{~g}$ respectively.

We observed an increase in degree of body mass index and weight gainin both broiler and domestic chicken diets groups; however the significance level was more in broiler chicken group (table-I).

The animals of group I and II gained almost equal weight $(187 \pm 17 \mathrm{~g})$ during study period while the weight gain in animals of group III was significantly higher $(229 \pm 17 \mathrm{~g})$ as compared to those of controls or groupII. Body weight gain with increasing age of animals in group III was significantly different while it was normal in rats of group I and II.

Comparison of mean body mass indexby Post hoc Tukey's HSD revealed that group III $\left(0.81 \pm 0.01 \mathrm{~g} / \mathrm{cm}^{2}\right)$ rats displayed significantly higher $(p \leq 0.001)$ measurements as compared to the group I rats $\left(0.61 \pm 0.03 \mathrm{~g} / \mathrm{cm}^{2}\right)$. The body mass index values in group I and II were not significantly raised ( $p=0.623)$ as shown in table-II. population as a pilot project, our results were more pronounced because of gender differences.

Our study also suggested that consumption of broiler chicken on daily basis may lead to oscillating levels of sex hormones. Estrogen as a pleiotropic hormone ${ }^{15}$, affects every system of the body and has profound effects on body metabolism. Studies showed that excess of estrogen is linked to disturbed metabolism which leads to inappropriate deposition of fats and adipose tissuehence causing obesity ${ }^{16}$. This can further be inferred from this fact that this may lead to insulin resistance, diabetes and dyslipidemias. Excessive estrogen in female can enhance proliferation of uterine lining and breast tissue which may be implicated as not good in perspective of malignancy ${ }^{17}$. This can further enhance the chances of anovulatory cycles and hence decreasing the fertility ratio in female population.

Broiler chicken contains extra cholesterol which acts like a substrate for the steroidogenesis ${ }^{18}$, thus balance is tipped towards increased production which control many regulatory pro-

Table-I: Comparison of anthropometric parameters in control and experimental groups.

\begin{tabular}{l|c|c|c|c}
\hline Variables & Group I (n=30) & Group II $(\mathbf{n}=\mathbf{3 0})$ & Group III (n=30) & $p$-value \\
\hline $\begin{array}{l}\text { Body Mass Index } \\
\left(\mathrm{g} / \mathrm{cm}^{2}\right) \text { Mean } \pm \text { SD }\end{array}$ & $0.61 \pm 0.03$ & $0.72 \pm 0.02$ & $0.81 \pm 0.01$ & $<0.001^{*}$ \\
\hline $\begin{array}{l}\text { Weight Gain } \\
(\text { Grams }) \text { Mean } \pm \text { SD }\end{array}$ & $190.27 \pm 17.57$ & $185.30 \pm 17.41$ & $229.17 \pm 16.88$ & $<0.001^{*}$ \\
\hline
\end{tabular}

*p-value $<0.05$ was significant.

Table-II: Intra-group association of variables among the control and experimental groups.

\begin{tabular}{l|c|c|c}
\hline \multirow{2}{*}{ Parameters } & \multicolumn{2}{|c|}{ Group-1 } & Group-2 \\
\cline { 2 - 4 } & Group-2 & Group-3 & Group-3 \\
\hline Body Mass Index $\left(\mathrm{g} / \mathrm{cm}^{2}\right)$ & 0.623 & $<0.001^{*}$ & $<0.001^{*}$ \\
\hline Weight Gain $($ Grams $)$ & 0.509 & $<0.001^{*}$ & $<0.001^{*}$ \\
\hline
\end{tabular}

\section{DISCUSSION}

The equilibrium of dietary proteins is shifting from red meat and fish to chicken meat. The results of our study showed that consumption of broiler chicken significantly increased body mass index and weight gain in male rats. Ahmad et al, 2016 also reported increase in weight gainin female Albino Wistar rats ${ }^{14}$. But as we have conducted study on male animal cesses in the body and also have been implicated as the cause of obesity. These hormones along with $\mathrm{GH}$, leptin, adiponectin and insulin interferewith our appetite and may modulate our behavior and preference ${ }^{19}$, over a particular diet and they also guide the distribution of fat. This chicken is reared on diets enriched with nutritional and non-nutritional ingredients. These ingredients hoard in chicken meat and in the consumer and could be the cause of disturbed 
metabolism and obesity. Chicken feed causes more muscle mass and abdominal obesity in broilers and this may reflect in consumers as well.

The results of our study showed significant increases in weight gain in broiler chicken meat fed group as compared to control and organic meat fedgroups. Growth, weight gain and body mass indexare said to be environmentally linked. Group III rats showed marked increase in body weight and body mass indexand was consistent with earlier reports and studies ${ }^{20}$.

Hormonal derangements because of consistent use of broiler chicken meat are reflected in terms of precocious puberty, and an increase in weight and growth rates ${ }^{21}$. This rise was however not seen in control and group II. The early growth spurt and obesity surge may be linked to increase in the rate of broiler chicken consumption on daily basis in Pakistani population. More general population in Pakistan is utilizing cholesterol and fats than proteins and hence imparting a majormass to the burden of obesity and weight gain ${ }^{22}$.

\section{CONCLUSION}

Based on the findings of our study we concludedthat broiler chicken meat consumption on regular basis could be the potential cause of out of proportion weight gain and growth spurt in experimental rats.

\section{CONFLICT OF INTEREST}

This study has no conflict of interest to be declared by any author.

\section{REFERENCES}

1. Wahyono N, Utami M, Editors. A review of the poultry meat production industry for food safety in Indonesia. J Phys Conf Ser 2018; 993(2): 1-5.

2. Henchion M, Hayes M, Mullen AM, Fenelon M, Tiwari B. Future protein supply and demand: strategies and factors influencing a sustainable equilibrium. Foods 2017; 6(7): 53-55.

3. Meat Consumption: Beef and veal / Poultry meat / Sheep meat, Kilograms/capita, 2018: The Organisation for Economic Cooperation and Development (OECD); [Internet]. Available from: [Accessed 26 Oct 2018]. https://data.oecd.org/agroutput/ meat-consumption.htm.

4. Sohaib M, Jamil F. An insight of meat industry in pakistan with special reference to halal meat: a comprehensive review. Korean J Food Scie Anim Resour 2017; 37(3): 329-41.
5. Wang Y, Lehane C, Ghebremeskel K, Crawford MA. Modern organic and broiler chickens sold for human consumption provide more energy from fat than protein. Public Health Nutr 2010; 13(03): 400-08.

6. Wang Y, Lehane C, Ghebremeskel K. Modern organic and broiler chickens sold for human consumption provide more energy from fat than protein. Public Health Nutr 2010; 13(3): 400-8.

7. Fouad A, El-Senousey H. Nutritional factors affecting abdominal fat deposition in poultry: a review. Asian-Australasian J Anim Sci 2014; 27(7): 1057-68.

8. Gonzalez-Moran MG. Immunohistochemical localization of progesterone receptor isoforms and estrogen receptor alpha in the chicken oviduct magnum during development. Acta Histochem 2015; 117(8): 681-87.

9. Ahmad S, Ahmed I, Haider S, Batool Z, Ahmed F, Tabassum S, et al. Effects of Consumption of Caged and Un-Caged Chicken Meat on Ovarian Health of Female Wistar Rats. Pak J Zool 2018; 50(2): 401-97.

10. Ahmad S. The effect of commercially available chicken feed and chicken meat on body weight and serum estrogen levels in female albino Wistar rats. Int J Livest Prod 2017; 8(2): 24-27.

11. Sengupta P. The Laboratory Rat: Relating Its Age With Human's. Int J Prevent Med 2013; 4(6): 624-30.

12. Health NIo. Guide for the care and use of laboratory animals: National Academies; 1985 [Internet]. https://grants.nih.gov/ grants/olaw/guide-for-the-care-and use of-laboratory-animals. pdf.

13. Novelli EL, Diniz YS, Galhardi CM, Ebaid GM, Rodrigues HG, Mani F, et al. Anthropometrical parameters and markers of obesity in rats. Laborat Anim 2007; 41(1): 111-19.

14. Ahmad S, Omm-e-Hany AI, Ahmed SA, Alamgir A, Neelam A. Potential Effect of Chicken Boneless Meat on the Body Weight and Serum Cholesterol Levels of the Female Albino Wister Rats: in Direct Human Prospective Studies. Am-Eurasian J Agric Environ Sci 2016; 16(03): 466-69.

15. Velarde MC. Pleiotropic actions of estrogen: a mitochondrial matter. Physiol Genom 2012; 45(3): 106-09.

16. Qiu S, Vazquez JT, Boulger E, Liu H. Hepatic estrogen receptor a is critical for regulation of gluconeogenesis and lipid metabolism in males. Scien Report 2017; 7(1): 1661-65.

17. Sánchez-Jiménez F, Pérez-Pérez A, de la Cruz-Merino L, Sánchez-Margalet V. Obesity and breast cancer: role of leptin. Front Oncol 2019; 9(2): 112-80.

18. Pihlajoki M, Heikinheimo M, Wilson DB. Regulation of Adrenal Steroidogenesis. Adrenal Disorders: Springer; 2018. p. 15-66. [Internet]https:// profiles.wustl.edu/en/publications/ regulation-of-adrenal-steroidogenesis.

19. Avila Carrasco L, Pavone MA, González E. Abnormalities in glucose metabolism, appetite-related peptide release and proinflammatory cytokines play a central role in appetite disorders in peritoneal dialysis. Front Physiol 2019; 10(1): 630-45.

20. Ahmad S, Omm-e-Hany AI, Ahmed SA, Alamgir A, Neelam A. Potential Effect of Chicken Boneless Meat on the Body Weight and Serum Cholesterol Levels of the Female Albino Wister Rats: in Direct Human Prospective Studies. American-Eurasian J. Am Eurasian J Agric Enviorn Sci 2016; 16(1): 466-69.

21. Calder PC, Ahluwalia N, Brouns F, Buetler T, Clement K. Dietary factors and low-grade inflammation in relation to overweight and obesity. British J Nutrit 2011; 106(S3): S1-S78.

22. Misra A, Jayawardena R. Obesity in south asia: phenotype, morbidities, and mitigation. Current Obesit Report 2019; 8(1): 43-52. 